\title{
Investing the Effects of Teachers' Gestures in Class
}

\author{
Wanting Dai ${ }^{1, \text { a, }{ }^{*}, \dagger}$ Yanle $\mathrm{Li}^{2, \text { b, }, *}$ \\ ${ }^{1}$ Information Management Institute, Nanjing University, Nanjing, Jiangsu Province, 210046, China \\ ${ }^{2}$ Language and Culture Institute, Tianhua College, Shanghai Normal University, Shanghai, 201800, China \\ *Corresponding author. Email: ${ }^{a} 181820029 @$ smail.nju.edu.cn , ${ }^{*}$ lilele18236838111@163.com
}

These authors contributed equally.

\begin{abstract}
The objective of this research is to learn how gestures using by the teacher affect students in class. In teaching practice, teachers or speakers tend to express more verbal information than gestures. Gestures also play an irreplaceable role in the teaching process, similar to "scaffolding". Whether in the understanding of knowledge or emotional communication, it can better connect the relationship between teachers and students. The research of this article uses gesture analysis, conversation analysis, and specific example analysis methods. We use a teaching video of a lower grade teacher to specifically analyze a series of gestures that appear in the classroom. These gestures are thumb up, point, and three special gestures. These types have strong guiding forces and representativeness. Then we will analyze them one by one in the following article. Our research uses a combination of video research, conversation analysis, and motion extension to further explore the meaning of gestures in the teaching process.
\end{abstract}

Keywords: Gesture, Class, Thumb up, Pointing, Other gestures

\section{INTRODUCTION}

The gesture is an indispensable auxiliary tool in the teaching process. If language is a bridge between teachers and students, gesture teaching is a part of the bridge and plays a stable role. As a non-verbal behaviour, gestures often appear in classroom teaching. The teaching gesture should be natural, concise, and accurate, which will play a very good auxiliary teaching effect and is widely accepted and loved by students. According to Gerard Nierenberg and Henry Calero, gestures convey attitudes and mood, and in the three-dimensional teaching objectives, it is connected with the emotional attitude and values [1].

\section{LITERATURE REVIEW}

Advantages of gestures are incomparable in class: First of all, gestures are usually accompanied by expressive stretching, which can shorten the distance between people in a short time. An open palm or palms up position "embodies an elicitation move on the part of the teacher, enacting an expansion of heterogeneous space, inviting student voices into the discourse [2]. In addition, some studies have shown that gestures and language are prepared jointly in children. The output of body language is developed from infancy and is preserved during the transition to the mother tongue [3]. All of the gestural reinforcements were paid to make the students improve their desired behaviours. Gestural reinforcement such as smiling could provide a more comfortable atmosphere for students in class [4].

Next, the younger students are playful and active, with short attention spans [5]. Teachers expect students to actively study and listen in class - students interact with the teacher or other students with full attention. In the initial stage of English learning, children are so full of curiosity and interest, but as the difficulty increases, they begin to treat English learning coldly and negatively [6]. Elementary school students prefer imitating and moving, which improves gestures to be useful, and they are always attracted to things in motion. For example, when teachers teach a new word or sentence, they can use "open the book; open the door [6]." In a word, vivid gestures combined with fluent English can create a safe learning environment, which will certainly positively improve students' learning abilities [6].

In addition to the above, what cannot be neglected is gestures help reinforce students' learning effects. This advantage can be seen from the following findings. In some ways, attitudes and emotions are what gestures can express [1]. By moving our hands and fingers, we express our thoughts and communicate with others [5]. Mustafa 
Altun indicates "see what I mean" in gesture when we point at things, and they allow students to follow teachers [1]. Flevares and Perry studied in 2001 about teacher's verbal explanation, and there are beans on a grid which she pointed(gesture) to, while this gesture expresses knowledge change in the classroom [7]. Besides, gestures help reinforce common concern and understanding [8]. As a result, gestures stop students' being absent-minded, which enables students to improve effects indirectly. What's more, in class, gestures play a role in building joint attention and negotiating vocabulary [9]. This benefit is demonstrating that students are easy to catch knowledge via gestures. Last but not least, gestures are inclined to be a scaffolding for teachers [10]. The teacher's and students' remarkable gestures, almost solely deictics and haptics, proved a type of language representation in an educational view. These gestures are liable to be a simple scaffolding device when teachers manage the class [11]. Gestures are also used to seek assistance and scaffold interlocutors [9]. These authors all emphasize the therapy of scaffolding which is applied in teaching. Hence, this is the charm of gestures.

In the recent decade, most papers and books focus on nonverbal language in class, and most researchers prefer studying the types and influences of gestures or what occasions may gesture appear. However, few studies one or a few specific gestures the teacher uses, similar to what we study below_- thumb up, point, and some specific gestures. Therefore, this research aims to fill in this research gap by analysing these three gestures.

\section{RESEARCH METHODS}

This research combines gesture analysis and conversation analysis to investigate applications and effects of gestures in class and takes three videos about classes in primary school uploaded on YouTube as examples. The first, uploaded in 2019, is about an 11minute-long 'Third Grade Read aloud' class, and about 20 students in the third grade [12]. The second is a literacy lesson called 'Literacy Lesson First Grade' around 20 minutes where there are about 20 students in the first grade, and this video is uploaded in 2016 [13]. While in the last video, about 22 second grade students have a PE lesson named 'Teaching Expectations in Elementary PE Through Movement', which is uploaded in 2018, and the video lasts [14].

\section{RESEARCH FINDING AND DISCUSSION}

\subsection{The Percentages of Gestures in the Data}

The gesture is a type of communicative tool used in varieties of occasions to achieve non-verbal language functions. In most cases, gestures act as a channel, especially between listeners and addressers. It is common to observe gestures in the class, while sometimes, they also play an important role in the case of political speech [15]. In some ways, political speeches are usually different from face-to-face communication. When someone is speaking, hand gestures are practical for expressing some language functions [16].

Table 1. The Percentages of Gestures in the Data

\begin{tabular}{|c|c|c|c|}
\hline Gestures & ency & Percentage & Context \\
\hline Thumb-up & 3 & $10 \%$ & $\begin{array}{l}\text { It is used by the } \\
\text { teacher when the } \\
\text { students answer } \\
\text { the question } \\
\text { correctly. }\end{array}$ \\
\hline 2. Pointing & 15 & $50 \%$ & $\begin{array}{l}\text { It is used by the } \\
\text { teacher when } \\
\text { he/she emphasis } \\
\text { pictures or words } \\
\text { or asks students to } \\
\text { answer the } \\
\text { question. }\end{array}$ \\
\hline 3. Other Gestures & 12 & $40 \%$ & $\begin{array}{l}\text { It is used by the } \\
\text { teacher when } \\
\text { he/she wants to } \\
\text { express } \\
\text { something from } \\
\text { his/her view. }\end{array}$ \\
\hline
\end{tabular}

In a teaching video called 'Literacy Lesson First Grade', gestures were used in different parts and accounted for different percentages. As is illustrated in the table above, it is evidently illustrated that the teacher in Literacy Lesson First Grade used three types of gestures such as thumb up (10\%), point (50\%), and some specific gestures such as crossing hands, closing hand, opening, and closing hands. The most used gesture is point $(50 \%)$. These gestures are advantageous for teachers to finish the class.

\subsection{Other Representative Gestures in the Data}

\subsubsection{Thumb up}

\section{Transcript 1:}

TEA(Teacher): What do you do when your classmate::: says something you agree with?

\section{STU(Student): $\langle\operatorname{xxxxxx}>$.}

TEA: Good job. All right, I agree. (The teacher gave a thumb-up gesture) Samantha, why is it important to take notes? (Samantha raised her hand.)

Samantha (Student): $\mathrm{It}^{\wedge}$ is important to take::: no^tes because If you um: forget about what I me^an. (The teacher thumbed up.)

TEA: If you forget something, what do you say that.

STU: $\langle\mathrm{xxxx}\rangle$. (Another girl raised her hand actively.)

TEA: $\langle x\rangle$. (The teacher pointed at the girl.) 
Samantha: It is important to take $\mathrm{no}^{\wedge}$ tes because: (0.1) you can write down: important infor^ ${ }^{\wedge}$ mation.

As is shown in the video, the teacher aimed to encourage students to read aloud, and in the following part, the teacher raised a question, and students answered together. Since they answered the question correctly, the teacher said 'good job' with a thumb-up gesture. Meanwhile, Samantha raised her hand and answered it correctly, which was why the teacher thumbed up. Then the teacher asked another question to all students, and when the others have not finished answering it, another girl could not help raising her hand, and when the teacher then called her name, she answered the question completely and quickly. From this part, it can be seen that the teacher wore a smile all the time, and with the addition of a thumb-up gesture, students gained encouragement, so the second girl was willing to take part in the class initiatively. As a result, what cannot be neglected is the thumb-up gesture is liable to enhance students' learning initiative to improve teaching effects. The teacher used gestures such as 'thumb up' to reply to students' behaviours, reinforcing and maintaining students' good behaviours [16].

\subsubsection{Pointing}

\subsubsection{The First Clip of Pointing}

\section{Transcript 2:}

TEA: I'm going to be::' kind ${ }^{\wedge}$, (The teacher pointed the picture with her left index finger.)

STU: ' I'm going to be::' kind ${ }^{\wedge}$,

TEA: with my big heart.

STU: ${ }^{\circ}$ with my big heart. (Students repeated the teacher's words and followed her actions.)

TEA: If I do th^ at, (The teacher threw up her hands.)

STU: ' If I do th^ at, (Students repeated the teacher's words and followed her actions.)

TEA: we're going to have fun. ((The teacher smiled and used two forefingers to draw arcs along her mouth, which turned to be a semicircle.))

As is shown in the video, the physical education teacher told students that if they want to enjoy their lesson, they should be kind, and in this process, students followed the teacher's words. At first, the teacher said, 'I'm going to be kind' with her left index finger pointing to the picture while the four right fingers are pointing to her heart, and after that, students repeated her words. Then she said 'with my big heart' with her right four fingers circling, and students repeated. In this way, the teacher intended to emphasize teaching students to be friendly in the class. As a result, in this process, the teacher expressed 'see what I mean' via pointing the picture to make students follow her [1]. Meanwhile, the gesture of point enables students to attach attention to words and participate in the class.

\subsubsection{The Second Clip of Pointing}

\section{Transcript 3:}

TEA: First it's a picture taken with a came^ra::: , there is a board $\mathrm{ga}^{\wedge} \mathrm{me}$, there are soft soft $\mathrm{cou}^{\wedge} \mathrm{ches}$. Look at the way that the people are $\mathrm{dre}^{\wedge} \mathrm{ssed}$. There are lots of differences between the two pictures.

As is shown in the video, the teacher pointed at the picture on the board, which aimed to illustrate the contents of the picture to students. With the movement of his middle finger, he showed from one item to another. In the meantime, students paid attention to the picture. In this way, gesture acts as a scaffolding for talkers [10]. Students can be aware of what the teacher is saying, and the teacher tends to make sure who is absent-minded.

\subsubsection{Other Gestures}

\subsubsection{The First Type of Other Gestures}

\section{Transcript 4:}

TEA: Already:(oh)what's that Ward without wish for the answer in your head it. happened^yesterday? It happened:(o) over a century ago.? It's not the present(0.1)It's not the future. It's the ${ }^{\wedge}(0.2)$

STU: Past:::

TEA: It's the past, good job (because of) this word, it happened (0.2) 100 years ago: do you. Remember? It happens ${ }^{\wedge}$ whoa, I see hands up already it happened ${ }^{\wedge} 100$ years ago, It has that soft $\mathrm{C}$ sound at the beginning to remember what it was, it happened 100 years ago, you remember what that word is you don't remember $(0.1)$ if you remember below the answer in your hand, what's that word for when it happened over 100 years ago released?

\section{STU: Century:::.}

As is shown in the video, when the teacher did this action, he waved his hands to draw the children's attention firstly. The teacher put his hand near to his mouth and took it as a circle "o" as figure 6 , as if to tell children of secrets as solemn, arousing students curiosity and interest in learning. In this clip, we can also pay attention to the teacher's eyes changed. I think this meaningful glance well with the action of putting his hand closed his mouth because the focus of the class is coming quickly. A single gesture with the other parts of the body to guide each other can improve the overall teaching efficiency. The same principle is the ups and downs of the teacher's voice, which will burst large energy. Some children imitating teachers to do this action, whether answer past or century, their voices are 
loud and confident, which also illustrates the appeal. This also shows the appeal of the action.

In the next ten seconds of the video, the teacher asked a student who sat in the front of the classroom, but she did not answer the question. Next, the teacher made the action of putting his close hand mouth and began to shake. The aim is to hope that the students will concentrate in class and not desert. Then he turned his eyes to the whole classroom. When Century came out, the teacher's hand changed to a five-finger opening, as if the problem had been solved in a flash. I also think that the gesture of the teacher holding his hand as a virtual fist to his mouth is very similar to holding a microphone, like a speaker and a leader, guiding and regulating the thinking and behavior of the whole class. Teachers constantly change and use gestures in the classroom, which is a way to improve classroom efficiency [17].

\subsubsection{The Second Type of Other Gestures}

\section{Transcript 5:}

TEA: Hocus-^pocus: :

STU: Everybody Hocus-pocus $\langle\mathrm{xxxxx}>$.

TEA: I heard some great answers^ ${ }^{\wedge}$ ho wants to share with us how things have changed since long ago. Remember we're going to listen to (0.4) Joseph Hollin things changed since a long time ago?

JH: In...in the past-<xxx>.

TEA: Good sentence starter in the past.

JH: There was no-no telephone.

TEA: In the past, ^ ${ }^{\wedge}$ there were no telephones. I like what Joseph said. Let's repeat.

As is shown in the video, As the action unfolded, the teacher said a sentence similar to a mantra, which was similar to a customary slogan between teachers and students. The students also sat in the same motion with their hands on top of their heads, and then everyone called "Hocus-pocus". The teacher led the students to do the action of placing their hands on top of their heads. The original intention was to stop the students who were discussing the topic. First of all, putting your hands together means closing and locking. Secondly, putting your hands on the top of your head has a compulsive sense of pressure, forcing the children to stop what they are doing now. Finally, considering the physical senses, speaking with hands on the head will make the speaker very uncomfortable.

The teacher asked a classmate named Joseph Hollin to answer the question. At first, the students would be a little timid, or it might be because of shyness, but whenever Joseph Hollin said a word, the teacher would repeat it to the class in a loud voice [18]. This ensures that every student can hear the questions answered by Joseph
Hollin clearly. In addition, the teacher's loud voice can also overshadow the whispering discussion below. Although the teacher has just done the action of placing his hands crossed and pressing down on the top of his head, the nature of children is not controlled, and the teacher needs more corrections and reminders. When the student finished answering, the teacher spread out his arms to let everyone participate and repeat this sentence, spreading your hands as inviting you.

\subsubsection{The Third Type of Other Gestures}

\section{Transcript 6:}

TEA: Show me fireworks when your book is open to the sto $^{\wedge}$ ry. What page is our story $\operatorname{start}^{\wedge}$ on? (The teacher opened and close his hands every second. )

STU: seventy-five:::.

TEA: Let's say it three times, seventy-fi^ ${ }^{\wedge} \mathrm{ve}$, seventyfive.

STU: [ seventy-fi^ ${ }^{\wedge} \mathrm{ve}$, seventy-five].

(The students followed the teacher to open and close their hands every second.)

TEA: Good.

As shown in the video, the teacher asked students to show 'fireworks' if they have opened to the page in the book of this story. 'Fireworks' is a kind of specific gesture that opens and closes hands every second. Then the teacher asked students the number of the page, and the students answered it correctly. In this process, students imitated the teacher's gesture, displaying that they have taken notice of his question. This gesture of 'fireworks' is so interesting that it can drive students to focus on the teacher. To some extent, this remarkable gesture acts as scaffolding in the class by which the teacher can easily handle matters of the class [11].

\section{CONCLUSION}

To sum up, our research topic is studying how gestures using by the teacher affect students in class, and we treat 'thumb up, point, specific gestures' as research objects. We have got some apparent findings. Firstly, Gestures are liable to draw students' interests and make them focus on the class. In addition, gestures can help instruct students to maintain good habits. Moreover, it seems that gestures play a role of scaffolding between the teacher and students. Our research wants to arouse more teachers' attention to the usage of gestures to raise teaching efficiency, and students' interest in gestures can be an emotional tool. We also wish to make students get the correct knowledge of meanings of gestures because it tends to make them be involved in the class more quickly and initiatively. 
Last but not least, we wish that instructors can take notice of training teachers to use gestures more frequently and properly, which can be a beneficial scaffolding. To be brief, if instructors can coach teachers how to and when to use gestures properly, and teachers know it, and students accept it accurately, the class environment can be gentle and enjoyable. As a result, students may easily be interested in the study, which may lead to students' contributions to the country in return in the future. Educational business, or even economic or other areas of the country may have a gradual development.

\section{REFERENCES}

[1] A. Mustafa, An Underestimated Tool: Body Language in Classroom during Teaching and Learning, J. International Journal of Social Sciences \& Educational Studies, 6 (2019)155-70.

[2] V. Lim, Fei, Analysing the teachers' use of gestures in the classroom: A Systemic Functional Multimodal Discourse Analysis approach, J. Social Semiotics, 29 (2017)1-29.

[3] S. Daniela, What Do Learners Make of Teachers' Gestures in the Language Classroom, J. Iralinternational Review of Applied Linguistics in Language Teaching - IRAL-INT REV APPL LINGUIST, 44 (2006)211-30.

[4] M. Pratiwi, S. Sudirman, \& L. Adnyani (2018). A STUDY OF THE REINFORCEMENT USED BY ENGLISH TEACHER IN 6A CLASS AT SD LAB UNDIKSHA SINGARAJA. International Journal Of Language And Literature, 2(3).

[5] A. Lazaraton, Gesture and Speech in the Vocabulary Explanations of One ESL Teacher: A Microanalytic Inquiry, J. Language Learning, 54 (2004): 79-117.

[6] H. Yang, On the Effective Way of Body Language in the Primary English Teaching, J. Atlantis Press, 2016.

[7] M. Singer, The Function of Gesture in Mathematical and Scientific Discourse in the Classroom, $M$. (2017).

[8] A. Martha, Managing Common Ground in the Classroom: Teachers Use Gestures to Support Students' Contributions to Classroom Discourse, J. ZDM, 51 (2019)1-14.

[9] L. Helen, R. Hampel, K. H. Agnes, Gesture in Speaking Tasks Beyond the Classroom: An Exploration of the Multimodal Negotiation of Meaning Via Skype Videoconferencing On Mobile Devices, J. System, 81 (2019).
[10] Bruner, J. (1978). The role of dialogue in language acquisition. The child's conception of language, 241-256.

[11] A. Rosborough, Understanding Relations Between Gesture and Chronotope: Embodiment and Meaning-Making in a Second-Language Classroom, J. Mind, Culture, and Activity, 23 (2016)1-17.Lingua Susastra,1(2020)31-40.

[12] Before you continue to YouTube. Youtube.com (2021). Retrieved 25 May 2021, from https://www.youtube.com/watch?v=0ItBYzJ5ymY $\& \mathrm{t}=256 \mathrm{~s}$.

[13] Before you continue to YouTube. Youtube.com. (2021). Retrieved 25 May 2021, from https://www.youtube.com/watch?v=NkxJSwa_b3A $\& \mathrm{t}=309 \mathrm{~s}$.

[14] Before you continue to YouTube. Youtube.com. (2021). Retrieved 25 May 2021, from https://www.youtube.com/watch?v=r06mW60aQ8 $\mathrm{k}$.

[15] Y. Hosoda, D. Aline, Positions and actions of classroom-specific applause, J. Pragmatics, 20(2010)113-148

[16] D. Frahesti, H. Natasha, Teacher's Reinforcement in Teaching English at High School Level, J.

[17] N. Hudson, Teacher gesture in a post-secondary English as a second language classroom: A sociocultural approach, J. Dissertations and Theses - Gradworks, (2011).

[18] Alibali, M. W., et al. Managing common ground in the classroom: teachers use gestures to support students' contributions to classroom discourse, J. ZDM ,51(2019)347-360. 